\title{
Pressure Effects on the Structural Evolution of Monatomic Metallic Liquid Hafnium
}

\author{
Sedat ŞENGÜL ${ }^{1}$ and Murat ÇELTEK ${ }^{2 *}$ \\ ${ }^{1}$ Trakya University, Faculty of Science, Edirne, Turkey \\ ${ }^{2}$ Trakya University, Faculty of Education, Edirne, Turkey
}

\begin{abstract}
Structural evolution of monatomic metallic liquid hafnium under high pressures of 0-50 GPa has been investigated by molecular dynamics (MD) simulations using the tight-binding (TB) many body potentials during rapidly solidified processes. The structural evolution and glass formation (GF) process have been analyzed by using pair distribution functions (PDF), Wendt-Abraham $\left(\mathrm{R}^{\mathrm{WA}}\right)$ parameter, Honeycutt-Andersen (HA) and Voronoi tessellation (VT) methods. When the system has been cooled with a cooling rate of $2 \times 10^{13} \mathrm{Ks}^{-1}$, the glassy states are obtained for $\mathrm{P} \leq 40 \mathrm{GPa}$ pressures and the crystalline phase is obtained at $\mathrm{P}=50 \mathrm{GPa}$ pressure. The number of face-centered cubic (fcc) and hexagonal close-packed (hcp) ( $\mathrm{fcc}+\mathrm{hcp}$ ) type bonded pairs increase dramatically, while the number of perfect icosahedra, distorted icosahedra and body-centered cubic (bcc) type bonded pairs decreases with increasing of pressure. This is an indication that the solidification process of the system begins with nucleation in the liquid and that nucleation growth with increasing pressure continues to develop. The results show that the variation of local atomic bonded pairs is of great importance to understand the glass formation and crystallization process. However, it has been observed that the applied high pressure (HP) weakened icosahedral order and increased the fraction of other clusters in glassy hafnium at low temperatures. Furthermore, it has been observed that all glass transition temperatures $\left(\mathrm{T}_{\mathrm{g}}\right)$, main bond types and main base clusters change with increasing pressure.
\end{abstract}

Keywords: Metallic Glasses, Glass Forming Ability, Molecular Dynamics Simulation, Pair Analysis, Pressure Effect, Hafnium.

\section{Mono-atomik Metalik Sıvı Hafniyumun Yapısal Gelişimi Üzerine Basınç Etkileri}

\section{$\ddot{\mathbf{O z}}$}

Mono-atomik metalik sıvı hafniyumun 0-50 GPa yüksek basınçları altındaki yapısal değişimi, hızlı katılaştırma süreci sırasında sıkı-bağlı çok cisim potansiyeli kullanılarak moleküler dinamik benzetimleri ile araştırılmıştır. Yapısal gelişim ve cam oluşum süreçleri çiftler dağılım fonksiyonları (PDF), Wendt-Abraham parametresi ( $\left.\mathrm{R}^{\mathrm{WA}}\right)$, Honeycutt-Andersen (HA) ve Voronoi tessellation (VT) metotları kullanılarak analiz edilmiştir. Sistem $2 \times 10^{13} \mathrm{Ks}^{-}$ ''lik bir soğutma oranı ile soğutulduğunda, $\mathrm{P} \leq 40 \mathrm{GPa}$ olan basınçlar için camsı yap1 ve P = 50 GPa basıncında da kristal faz elde edildi. Basıncın artmasıyla, yüzey merkezli kübik (fcc) ve altıgen sıkı paketlenmiş (hcp) (fcc + hcp) tipi bağlı çiftlerin sayısı çarpıcı bir şekilde artarken, mükemmel icosahedra, bozuk icosahedra ve cisim merkezli kübik (bcc) tipi bağlı çiftlerin sayısı azalmıştır. Bu, sistemin katılaşma sürecinin sıvıda çekirdeklenme ile başladığını ve artan basınçla çekirdeklenmenin gelişmeye devam ettiğini gösterir. Sonuçlar, yerel atomik bağlı çiftlerin varyasyonunun, cam oluşumu ve kristalleşme sürecinin anlaşılması açısından büyük önem taşıdığını göstermektedir. Bununla birlikte, uygulanan yüksek basıncın icosahedral düzeni zayıflattığı ve düşük sıcaklıklarda camsı hafniyumdaki diğer kümelerin sayısını arttırdığı gözlenmiştir. Ayrıca, cam geçiş sıcaklıklarının $\left(T_{g}\right)$, ana bağlı tiplerin ve ana temel kümelerinin artan basınçla değiştiği gözlenmiştir.

Anahtar kelimeler: Metalik Camlar, Cam Şekillendirme Yeteneği, Moleküler Dinamik Simülasyon, Çift Analizi, Basınç Etkisi, Hafniyum. 


\section{Introduction}

It is difficult to characterize liquid structures because they do not have a long atomic order. Within a few $\AA$, the short-range atomic order (SRO) can be captured with analysis method, such as PDF [1]. Understanding the local structure of stable and supercooled melt systems are very important to understand crystallization process and glass formation from the melt as well as the properties of the liquid itself [2]. In the last four decades, researchers have been able to successfully obtain bulk metallic glasses (BMG) by applying rapid quenching methods to multi-component melts containing three or more elements[3-5]. On the other hand, although obtaining BMGs from binary alloys is limited, obtaining BMG from pure metals requires more effort[6,7]. Recently, Zhong et al.[8] successfully have obtained monatomic metallic glasses (MG) by quenching metals such as liquid tantalum and vanadium at an unprecedentedly high quenching rate of $10^{14} \mathrm{Ks}^{-1}$ with an experimental approach. It is well known that it is almost impossible to directly measure and observe the motion of atoms and atomic clusters in experiments. These difficulties and adversities overcome with molecular dynamics (MD) simulation as an alternative approach to study the dynamics of supercooling on the atomic scale[9, 10]. Together with the developing technology and the HP techniques, today the pressure for the condensed phases has become an important variable such as temperature[6]. In the past years, microstructural changes on these systems have been successfully explained by applying HP to many monatomic metals using MD simulation method[11-18]. The world is experiencing a digital revolution, and this revolution continues to progress rapidly from day to day. Today, leading companies, such as Intel and IBM, have begun using hafnium microchips to make their transistors faster and reduce leakage rates, rather than silicon microchips. Hafnium and its alloys have a high neutron absorption cross-section of $105 \times 10^{-28} \mathrm{~m}^{2}$ and are therefore used as neutron poisons in the control rods of nuclear reactors [19]. Hafnium is used to make binary compounds which are very good refractory materials. These materials have the capacity to endure high temperatures and high levels of pressure. Because of these unique properties, they are used in aerospace and similar fields. In addition, the hafnium is used by the computer industry to create smaller and smaller microchips that work much more efficiently with less energy. In order to ensure safe service of these materials, it is necessary to understand the characteristics such as the development of displacement cascades and the formation of vacancy under irradiation [19]. It is very difficult to make in-situ observation because this process is very short and the service condition of reactors is formidable[20]. A numerical method such as MD simulation is used as an alternative method to understand the effects of irradiation of materials [20-22]. Although the hafnium element has similar properties to the $\mathrm{Ti}$ and $\mathrm{Zr}$ elements, the high-pressure experimental studies on hafnium are fewer than others. First, Bakanova et al. [23] have shown that there are two phase transitions in hafnium at different pressures and temperatures. Ming et al. [24] observed no any transitions up to $39.5 \mathrm{GPa}$ in their pressure experiments on hafnium. Later, Xia et al.[25] showed that two-phase transition occur at high pressures by compressing hafnium in a diamond anvil cell using energy dispersive X-ray diffraction technique. Although in recent years there have been studies of HP polymorphism in this element, the local structure of the melt under HP has not yet been fully understood[26]. Based on our current knowledge, there is no MD simulation study of the effects of HP on the local atomic structure of the system during the cooling of the hafnium element. Thus, in this work, we have examined how the structural development of hafnium is changes under pressure and with temperature, and the results obtained are given in the following sections.

\section{Simulation Methods}

To study the effect of pressure on hafnium during rapidly solidified processes, the classical MD code DL_POLY 2.0 was used [27]. The cooling run was performed in the NPT ensemble (constant number of particles, pressure and temperature) with the given pressure. The simulation cell was a cubic box with periodic boundary conditions applied in three directions and contains 8664 atoms that were initially arranged in an ideal hep structure. The simulation was started at $3500 \mathrm{~K}$, which is well above the experimental melting temperature $\mathrm{T}_{\mathrm{m}}=2504 \mathrm{~K}$ [28] of hafnium, under $0 \mathrm{GPa}$. Firstly, the system in liquid state was equilibrated at $3500 \mathrm{~K}$ for 2,000,000 steps under the NPT ensemble for at least $2 \mathrm{~ns}$, the system quenched with cooling rate of $2 \times 10^{13} \mathrm{Ks}^{-1}$ from $3500 \mathrm{~K}$ to $300 \mathrm{~K}$ with an increment of $100 \mathrm{~K}$ was subjected to different external hydrostatic pressures $(P=0,5,10,20,30,40$, and $50 \mathrm{GPa})$. Structural evolution of liquid hafnium under the different pressures was investigated by MD simulations using TB 
potentials [29] during cooling process. Based on TB model, the total energy of a single atom can be divided into two parts:

$$
E_{C}^{i}=\sum_{i}\left(E_{R}^{i}+E_{B}^{i}\right)
$$

One is the repulsive potential:

$$
E_{R}^{i}=\sum_{j} A \exp \left[-p\left(\frac{r_{i j}}{r_{0}}-1\right)\right]
$$

The other is the attractive potential to bind atoms together:

$$
E_{R}^{i}=\left\{\sum_{j} \xi^{2} \exp \left[-2 q\left(\frac{r_{i j}}{r_{0}}-1\right)\right]\right\}^{1 / 2}
$$

where $\mathrm{r}_{\mathrm{ij}}$ represents the distance between atoms $\mathrm{i}$ and $\mathrm{j}$; and $\mathrm{r}_{0}$ is the first-neighbor distance. A, $\mathrm{p}, \zeta$, and $\mathrm{q}$ are model parameters connected with the physical properties of the elements. More details for the potential parameters can be found in Ref.[30-34]. TB many body potential parameters for hafnium used in our simulations have been taken as $\mathrm{A}=0.1323 \mathrm{eV}, \xi=2.1516 \mathrm{eV}, \mathrm{p}=10.557, \mathrm{q}=1.961$ and $\mathrm{r}_{0}=3.14 \AA$ as given in Ref. [35].

\section{Results and Discussions}

\subsection{Pair Distribution Function (PDF)}

The PDF, $g(r)$ showing the probability of finding another atom at a distance $r$ from an origin atom. It is often used to characterize the structural properties of liquids and noncrystalline solids, and the total PDF is defined as:

$$
g(r)=\frac{V}{4 \pi r^{2} N^{2}}\left\langle\sum_{i} \sum_{i \neq j} \delta\left(r-r_{i j}\right)\right\rangle
$$

where $\mathrm{N}$ is the number of atoms in the system. Figures 1(a)-1(f) display the temperature-dependent evolution of the PDFs obtained under 0-50 GPa. For the model system, the PDF curves at high temperatures carry characteristic liquid properties under all pressures. That is, the first peaks of PDF curves are salient and the second one is smooth. A splitting can also be seen in the second peaks of the PDF curves of the system cooled under $0 \mathrm{GPa}$ pressure at about $1300 \mathrm{~K}$, which is known as a characteristic feature of amorphous systems[34, 36]. These splitting become more pronounced with decreasing temperature. When the system is cooled with pressures of $10 \mathrm{GPa}$ and $30 \mathrm{GPa}$, it usually behaves similarly to $0 \mathrm{GPa}$. Unlike $0 \mathrm{GPa}$, at lower temperatures, a shoulder begins to form on the left side of the second maximum peak of the PDF curves, indicating that the glassy structure is not fully stabilized. These shoulders become more pronounced with increasing of the pressure. This case is also an indication that the number of crystalline clusters in the system is beginning to increase. The solidification process of the metals begins with nucleation in the liquid, and then develops with nucleus growth[37]. In order to obtain glassy hafnium under a high pressure, the melt hafnium has to be cooled at a high cooling rate. When the pressure is increased to a value as high as $50 \mathrm{GPa}$, it can be seen that the system transforms from the liquid to the crystalline structure during rapid cooling. In other words, when the crystallization started, the order degree of the system increased, and finally a crystalline structure has appeared obviously. Figures 2(a) and 2(b) show the PDF results obtained under different pressures at $2500 \mathrm{~K}$ and at $300 \mathrm{~K}$, respectively. PDF curves obtained at $2500 \mathrm{~K}$ under pressures of 0 $40 \mathrm{GPa}$ exhibit peaks belonging to liquid structures. When the system cooled under the pressures of 10$40 \mathrm{GPa}$, with decreasing temperature, a splitting at the second peak of the PDF curve and a shoulder between the first and second peaks of the PDF begin to appear, indicating that the system has undergone significant changes in its microstructure. Finally, at $300 \mathrm{~K}$, when the pressure is increased step-by-step from 0 to $40 \mathrm{GPa}$, it appears that the system still has a glassy structure, while the shoulder that forms with increasing pressure becomes even more pronounced. These results mean that with the increase in 
pressure, the distance between the atoms within the system decreases, the order degree of glassy hafnium decreases, and the crystal nucleation in the system continues to increase. It can be seen clearly in Figure 1(f) that PDFs obtained at $50 \mathrm{GPa}$, which is the highest pressure applied in this study, are different from the others. In the PDF curves obtained at this pressure, a sharper and more pronounced new peak appears at the position of the shoulders formed in the other pressures, indicating that this system is crystallized.
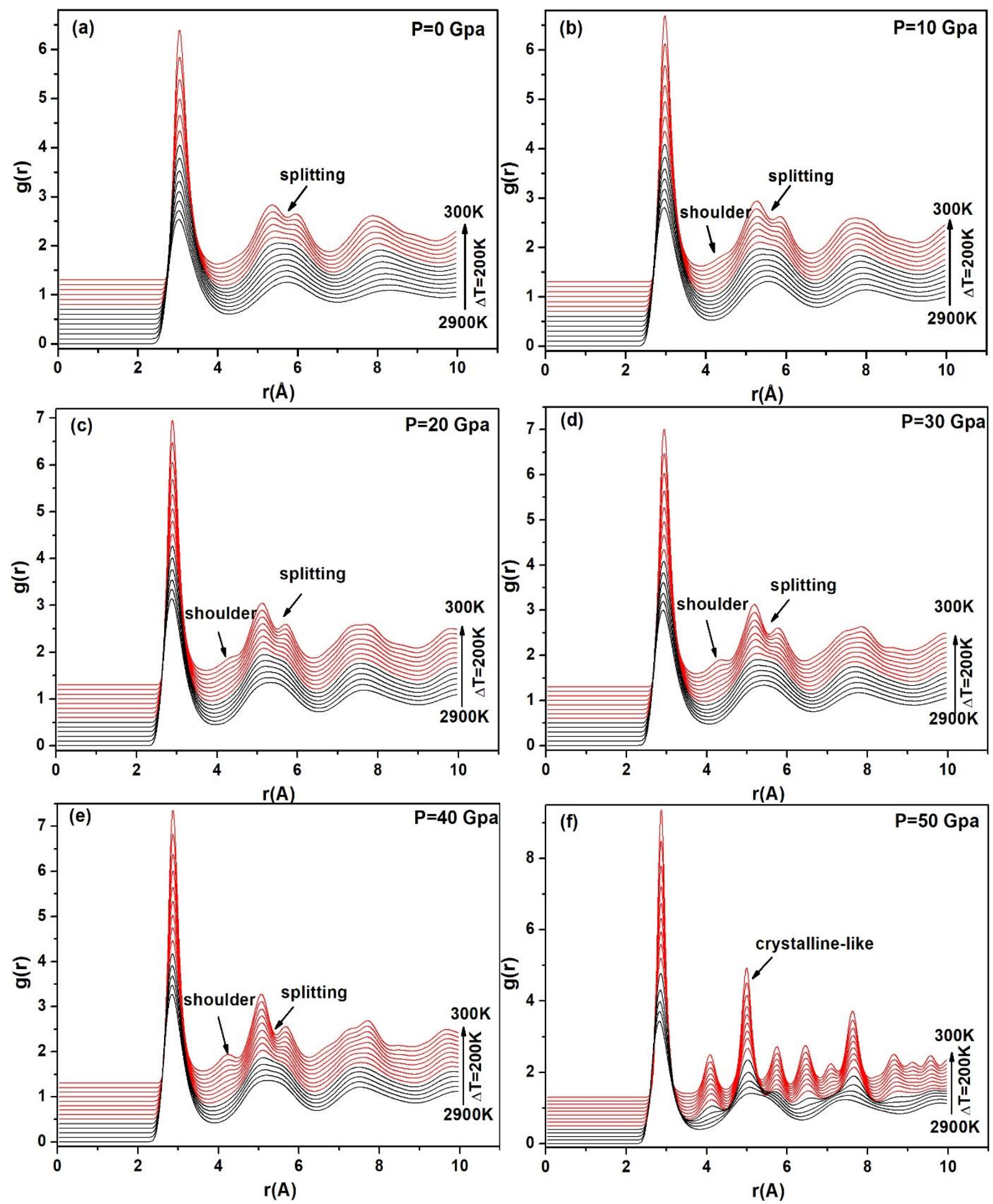

Figure 1. (Color online) The temperature-dependent changes of PDFs under the pressures of 0-50 GPa for monatomic hafnium. 

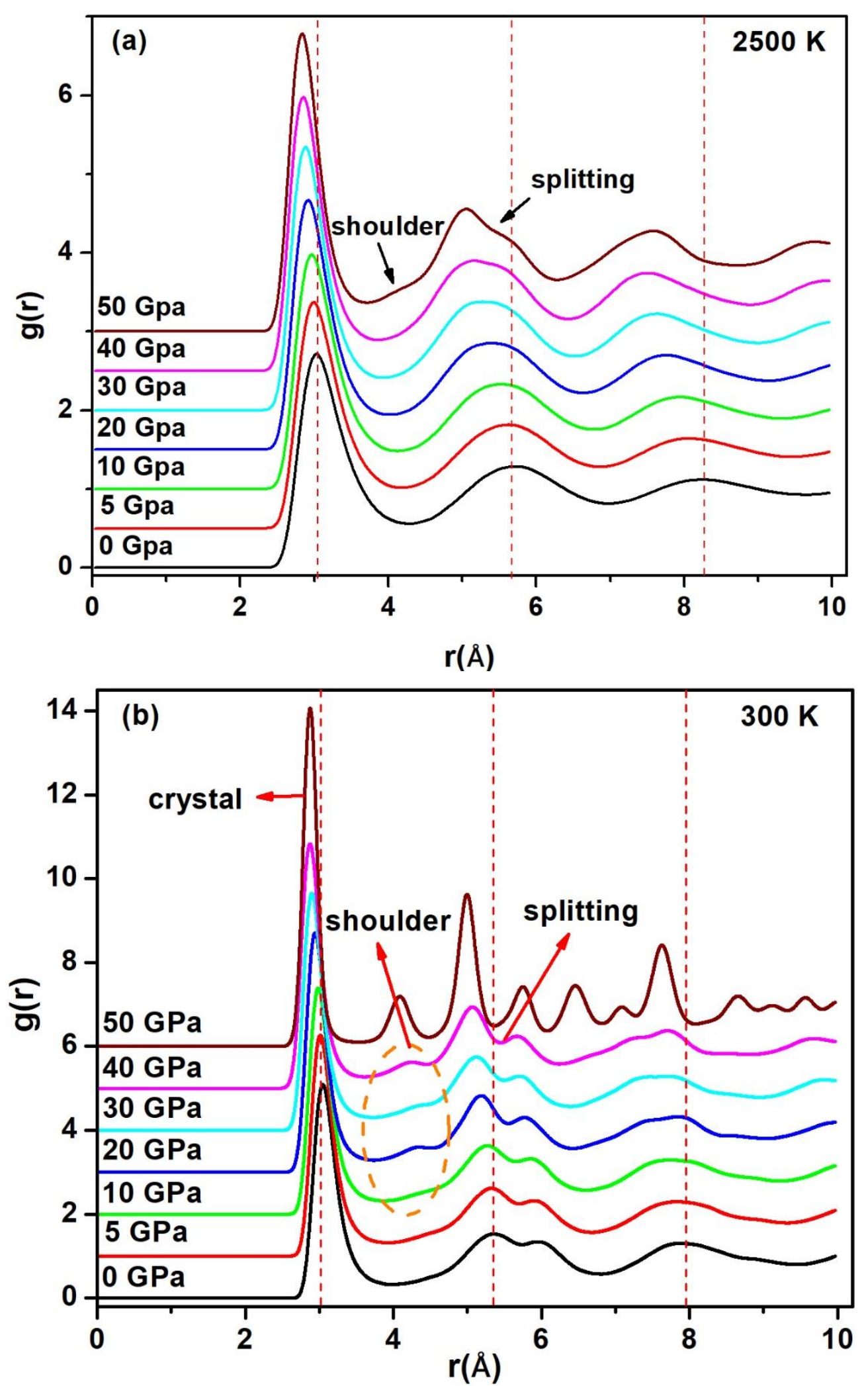

Figure 2. PDFs of the metallic liquids during isobaric pressure of 0-50 GPa, (a) at $2500 \mathrm{~K}$, and (b) at $300 \mathrm{~K}$.

The first and second maximum heights of $g(r)$ increase with increasing pressure and the corresponding 1st and $2 n d r_{\max }(\AA)$ positions shift towards smaller $r$ values, as shown in Figures 2 (a) and 2(b). These sharp increases in the peaks of the PDFs along with the increased pressure show that the SRO in the system is strengthening and that the crystal nucleation continues to increase and finally the system is 
crystalline. In addition, inward shifts in the first and second peaks of the PDF mean that higher pressures suppress the distance between atoms. It is clear that HP makes the distance between atoms shorter and the ordering degree in liquid, amorphous and crystal hafnium stronger.

\subsection{Glass formation}

It is very important to determine the $T_{g}$ correctly, because $T_{g}$ is probably one of the most important properties of amorphous systems and also determines the processing and working temperature range of the material. Before analyzing the microstructures of the system, we analyzed the evolution of the total energy (E) per atom as a function of temperature (T) during cooling, as shown in Figure 3.

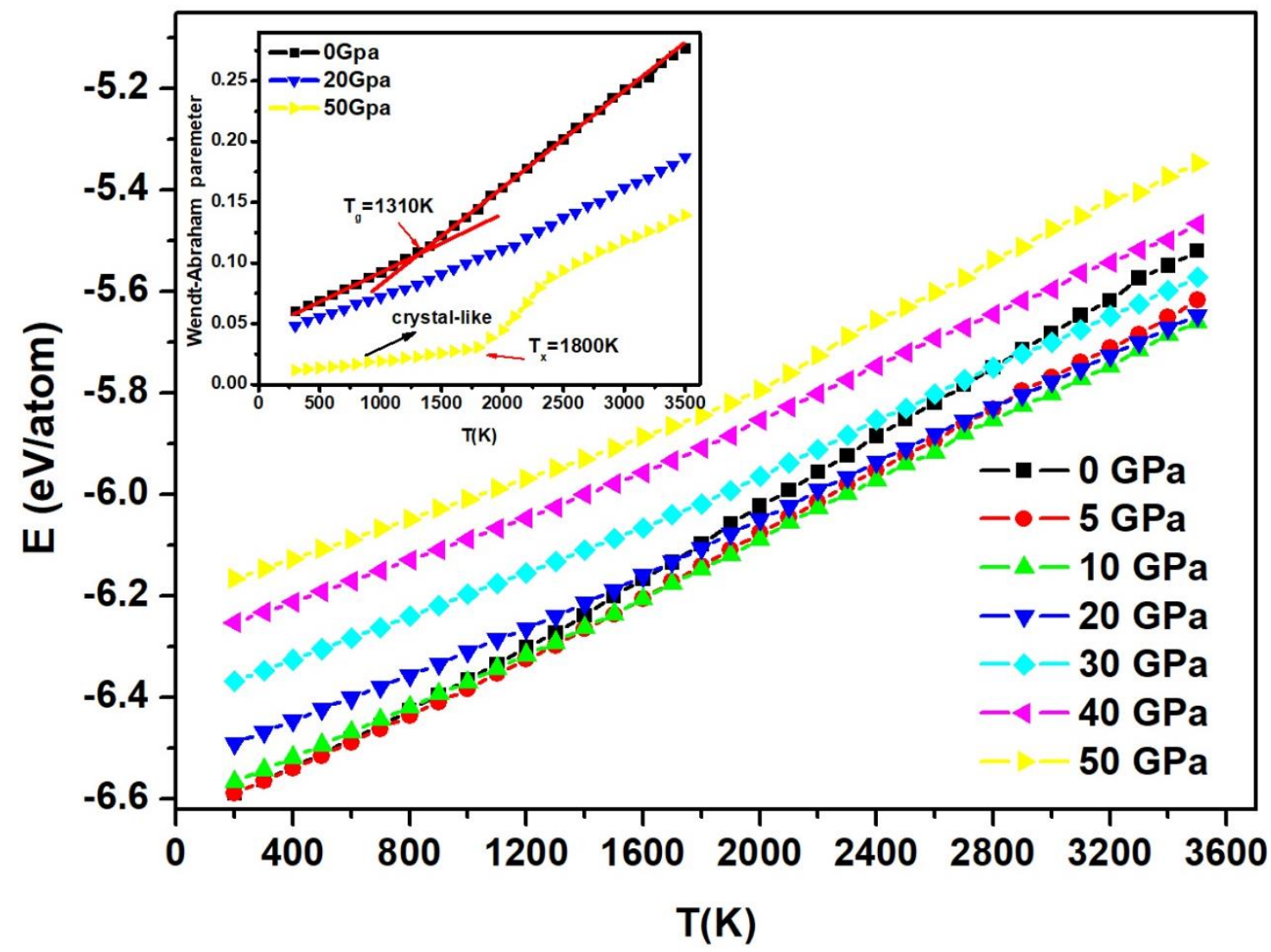

Figure 3. (Color online) Temperature dependence of total energy per atom of the liquid hafnium system under the pressures of 0-50 GPa. The inset shows the variation curves of $\mathrm{R}^{\mathrm{WA}}$ parameters according to temperature under the pressures of 0,20 and $50 \mathrm{GPa}$.

At pressures below $50 \mathrm{GPa}$, a sharp change in the energy curves cannot be observed, a slight change between $2400 \mathrm{~K}$ and $1800 \mathrm{~K}$ at $50 \mathrm{GPa}$ is observed, indicating the first order phase transition, such as crystallization. This phase transition can be seen in more detail than the temperature-dependent variation of the Wendt-Abraham (WA) parameter, as shown in the inset of Figure 3. Different methods have been used to evaluate the $\mathrm{T}_{\mathrm{g}}$ of glass systems in MD simulations. In our study, we used the WA parameter $\left(\mathrm{R}^{\mathrm{WA}}=\mathrm{g}_{\min } / \mathrm{g}_{\max }\right)$, which is commonly preferred to better determine $\mathrm{T}_{\mathrm{g}}$. Where $\mathrm{g}_{\min }$ and $\mathrm{g}_{\max }$ show the first minimum and maximum values of the PDFs, respectively. It can be clearly seen that the $\mathrm{R}^{\mathrm{WA}}$ values obtained under different pressures decrease with decreasing temperature. $\mathrm{R}^{\mathrm{WA}}$ curves have two lines with different slopes for pressure values of $0 \mathrm{GPa}$ and $20 \mathrm{GPa}$. There is a change in slope between low and high temperatures. With increasing pressure, the slopes of the $\mathrm{R}^{\mathrm{WA}}$ curves towards lower temperatures are similar but the slope towards higher temperatures continues to decrease. We observed a sudden and sharp decline in the $\mathrm{R}^{\mathrm{WA}}$ curve of the system cooled under $50 \mathrm{GPa}$ pressure between 2300 $\mathrm{K}$ and $1800 \mathrm{~K}$, which is an indication of the transition from liquid phase to solid phase. We have taken the final point of sudden decline as the crystallization temperature value (nearly $T_{x}=1800 \mathrm{~K}$ ). As can be seen in the inset of Figure 3, at high and low temperatures, the $\mathrm{R}^{\mathrm{WA}}$ curves have two different slopes, 
and the linear lines are plotted on data sets with different slopes, and the intersection of these linear lines is determined as $\mathrm{T}_{\mathrm{g}}$. For $0,5,10,20,30$, and $40 \mathrm{GPa}$, the evaluated $\mathrm{T}_{\mathrm{g}}$ values are $1310 \mathrm{~K}, 1340 \mathrm{~K}, 1375$ $\mathrm{K}, 1422 \mathrm{~K}, 1506 \mathrm{~K}$ and $1590 \mathrm{~K}$, respectively. We have observed a systematic relationship between pressure and $\mathrm{T}_{\mathrm{g}}$. In other words, $\mathrm{T}_{\mathrm{g}}$ has increased with increased pressure.

\subsection{Honeycutt-Andersen (HA) Bond-Type Index Method}

Although PDF gives a general definition of the crystallization process only from the liquid to the crystal structure, it does not accurately describe the structural changes and structure of the atomic clusters. Alternative methods are available to define the microscopic local structure and the SRO of structures by using Honeycutt-Andersen (HA) index [38] and Voronoi tessellation (VT) methods [39]. From these methods, the HA index consists of 4 integers such as $i j k l$. If the distance between the atom pair is less than $\mathrm{r}$, which corresponds to the first minimum value of $\mathrm{g}(\mathrm{r})$, then the first integer $i$ is 1 when the atom pairs are bonded in the root pair, otherwise $i$ is 2 . The second integer $j$ is the common-neighbor number of the considered pair. The third integer $k$ is the number of bonds among the shared neighbors. The fourth integer $l$ is used to distinguish structures that have the same first three indices but which have different geometries (eg, 1421 and 1422). According to these definitions, the index 1551 characterizes a part of the perfect icosahedra (icos) local ordering, while the indices 1541 and 1432 characterize the defect icosahedra (deficos) ordering. The 1421 index represents the fcc ordering and the 1422 index represents hcp ordering, while the 1661 and 1441 indexes represent the bcc ordering. Refs[30, 40] can be used for more detailed information. Figures 4(a)-4(f) show the statistical results of several prevalent HA indices under different pressures during the rapid cooling process of liquid hafnium. The results of the rapidly cooled system under zero pressure $(\mathrm{P}=0 \mathrm{GPa})$ show that at all temperatures, the icos $(1551)$ and deficos (1431 and 1541) bonded pairs are dominant, as in Figure 4(a). Overall, the SRO of the system under zero pressure is increasing with decreasing temperature, which is consistent with the PDF results discussed above. At the same time, the icosahedral ordering is the major part of the local structures in the system at all times. The distribution of 1541 bonded pairs increase from $18.74 \%$ at 3500 $\mathrm{K}$ to $24.72 \%$ at $300 \mathrm{~K}$ during cooling process, while the distribution of 1431 bonded pairs changes slightly from $21.91 \%$ at $3500 \mathrm{~K}$ to $20.13 \%$ at $300 \mathrm{~K}$. The one of the most important changes due to decrease temperature, the fraction of icos (1551) types increases from $15.08 \%$ at $3500 \mathrm{~K}$ to $22.61 \%$ at $1300 \mathrm{~K}$, while the fraction of 1551 bonded pairs drops to $18.47 \%$ at $300 \mathrm{~K}$ the starting from $1300 \mathrm{~K}$. However, the fraction of 1422- and 1421-type pairs appear to be insensitive to temperature between $3500 \mathrm{~K}$ and $1300 \mathrm{~K}$, while the fraction of 1422 and 1421 bonded pairs begins to increase significantly at temperatures below $1300 \mathrm{~K}$. This is an indication that the system has significant changes in its microstructure and that crystal-like clusters have begun to increase. On the other hand, the fraction of the bcc-like 1441 and 1661 bonded pairs is almost unchanged or changes very little as temperature drops. The results of $10 \mathrm{GPa}$ are similar to the results at $0 \mathrm{GPa}$, but the number of 1421 bond-type increased remarkably, while the number of 1551 bond-type decreases sharply with the decrease of temperature. When the pressure is increased from $20 \mathrm{GPa}$ to $40 \mathrm{GPa}$, the number of 1541 bond- pairs increases at first and then decreases with the increasing of the pressure and the decreasing of the temperature. The fraction of 1421 bond-type belonging to the fcc structure under $50 \mathrm{GPa}$ pressure increased very fast from $5.84 \%$ at $3500 \mathrm{~K}$ to $61.59 \%$ at $300 \mathrm{~K}$. On the other hand, the fraction of all other bond-types decreases as temperature drops. From these results, it can be clearly seen that the system has transitioned from liquid to crystal structure under the pressure of $50 \mathrm{GPa}$. The sum of icosahedra types icos+deficos 1551 , 1431 and 1541, fcc+hep types 1422 and 1421, and BCC types 1441 and 1661 are shown as a function of the temperature in Figures 5(a), 5(b) and 5(c). The fcc+hcp types of bond pairs increase dramatically, whereas the icos+deficos and BCC types of bond pairs decrease with the decreasing of the temperature. On the other hand, the number of fcc+hcp crystal clusters become even more pronounced both with increasing pressure and decreasing temperature. This is consistent with occurring a shoulder after the 1st minimum of the PDF curves discussed in the above section. As seen in Figure 5 (c), this decline is offset by an increase in icos + deficos types. According to this, it can be said that some of fcc + hcp crystal clusters transformed to icos + deficos type clusters at around $30 \mathrm{GPa}$. This explains why the left shoulder in the PDF is less obvious (please see Figure 2). 

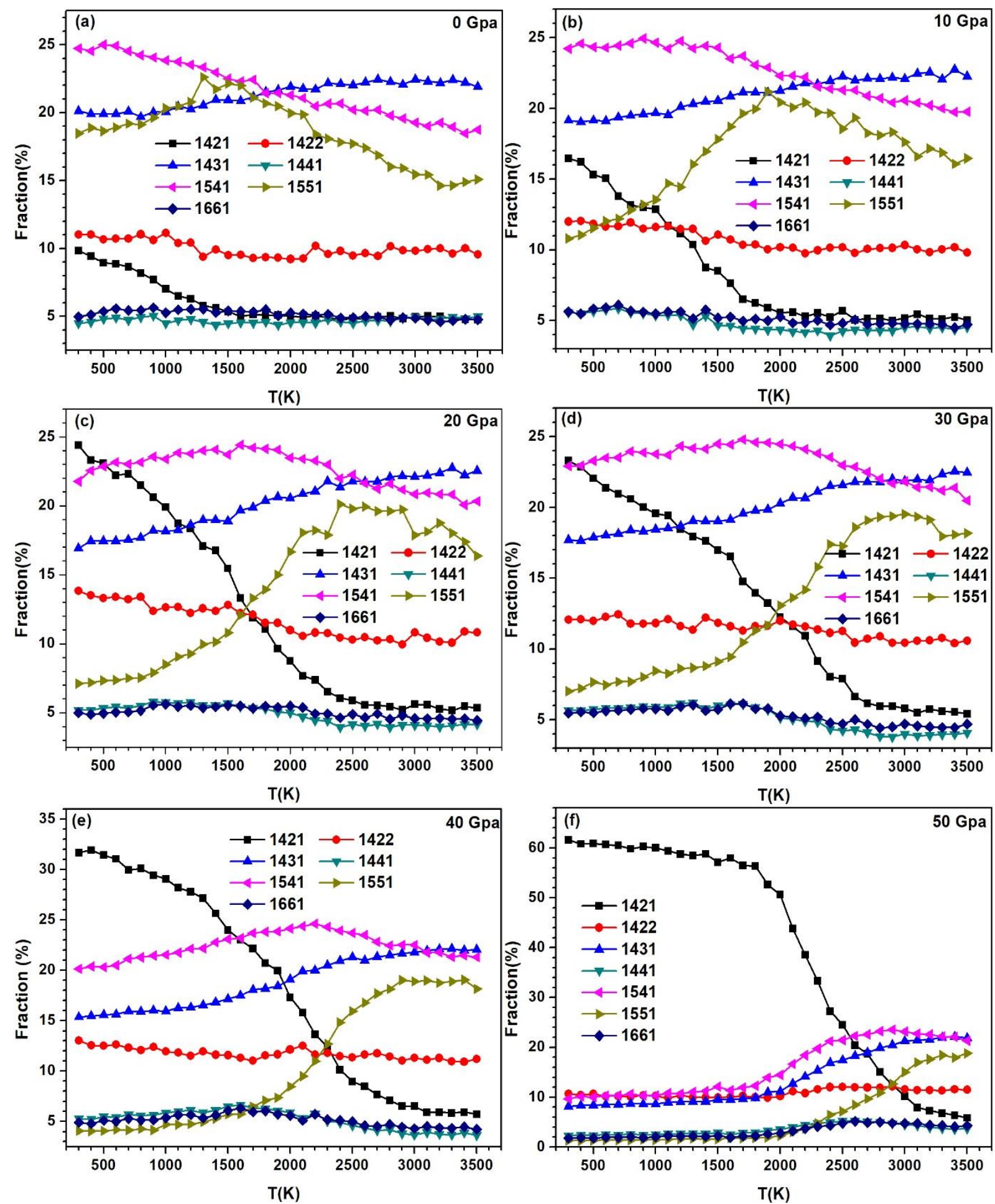

Figure 4. (Color online) Temperature dependent fraction of common HA indices obtained under the pressures of 0-50 GPa for monatomic hafnium.

The sudden and sharp increase in the fcc+hcp type clusters of the system cooled under 50 GPa pressure shows that the system undergoes from liquid to fcc+hcp crystalline structure. From MD simulation results, it can be seen that the increased pressure causes the increase of the fraction of the crystalline clusters together with the decrease of the fraction of the icosahedral clusters in the system and the high pressure causes the clusters in the system to transforms from the icosahedral to the crystalline structure. Furthermore, the high pressure strengthens the ordering degree in the liquid system, which is consistent with the fact that the first peaks of the PDF curves are more coordinated under pressure. Figure 5(d) represents the distribution of the various bonded pairs (1421, 1422, 1441, 1661, 1431, 1541, and 1551) 
formed at $300 \mathrm{~K}$ under different pressures ranging from $0 \mathrm{GPa}$ to $50 \mathrm{GPa}$. It can be seen that the icos (1551) or deficos (1431 and 1541) structures in the system dominate at $20 \mathrm{GPa}$ and lower pressures. The fraction of fcc+hcp types $(1421+1422)$ of bond-pairs increases remarkably with pressure, while the fraction of icos+deficos types $(1551+1431+1541)$ of bond-pairs decreases. Moreover, it can be observed that the 1441 and 1661 (bcc-like type) bond pairs also exist, and are the most abundant next to the icos+deficos types and fcc+hcp types. The most interesting of these is that as the pressure increases, the fraction of the fcc-like (1421) bond pairs increases from $9.84 \%$ at $0 \mathrm{GPa}$ to $62.59 \%$ at $50 \mathrm{GPa}$, while the fraction of the perfect (1551) bond pairs decreases from $18.47 \%$ at $0 \mathrm{GPa}$ to $1.29 \%$ at $50 \mathrm{GPa}$. This case can be explained as a transition of system from liquid to crystal structure at high pressure $(\mathrm{P}=50 \mathrm{GPa})$. The glassy hafnium formed under high pressures has a weakened icosahedral order, enhanced fcc+hcp crystalline type order and therefore has a lower thermal stability. Figure 6 illustrates the evolution of crystal-like clusters in the system under different pressures at $300 \mathrm{~K}$. The snapshot of the simulation box's has been rendered with the OVITO software [41]. It can be clearly seen that the pressure has a significant influence on the formation and evolution of microstructures, especially the relations of relative percentage of the main bond-types in the system.
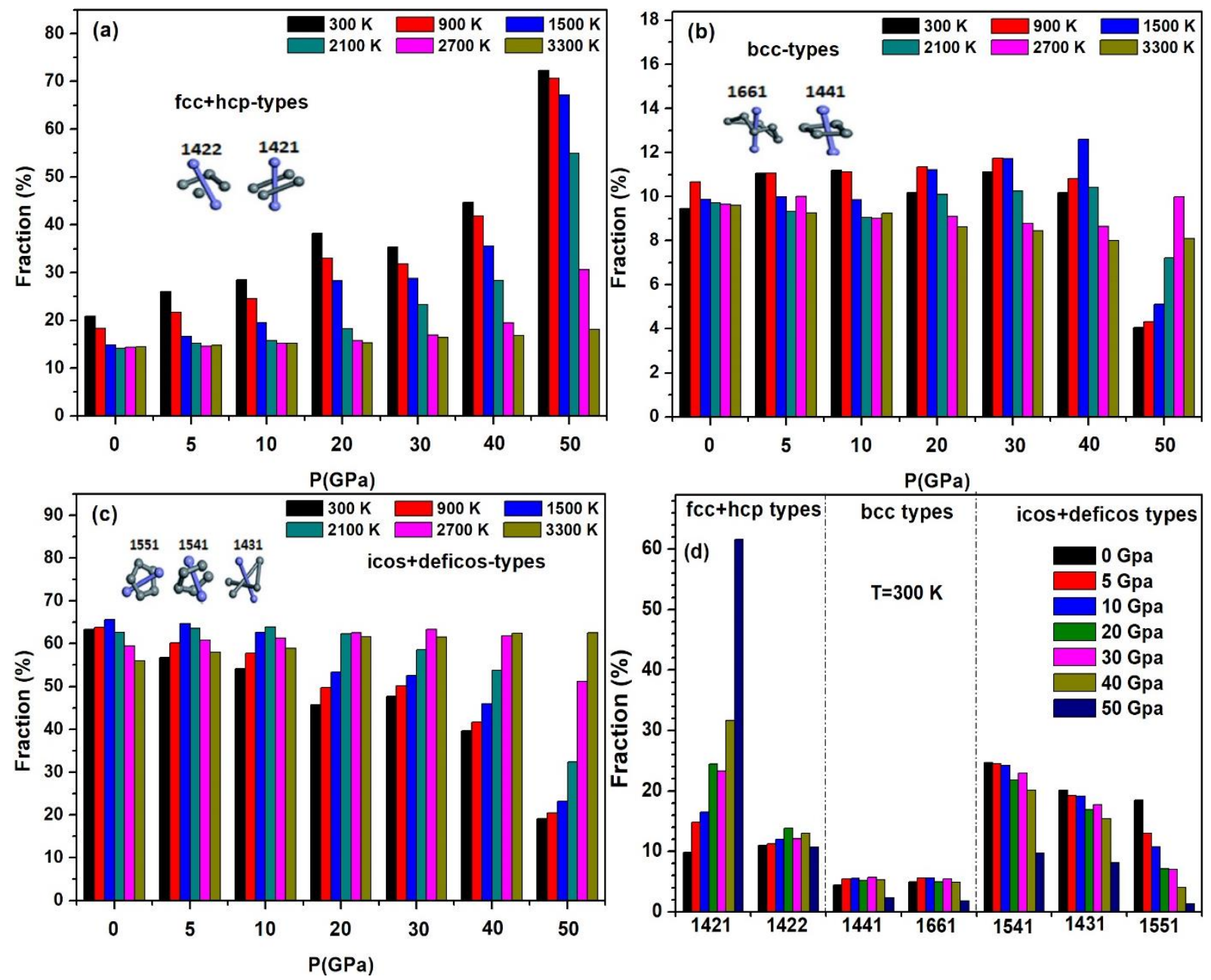

Figure 5. (Color online) The relative number of bonded pairs in bulk hafnium under different pressure as a function of temperature. (a) fcc+hcp, (b) bcc, and (c) icos+deficos types and (d) the distribution and variation of various bonded pairs under different pressures at $300 \mathrm{~K}$. 

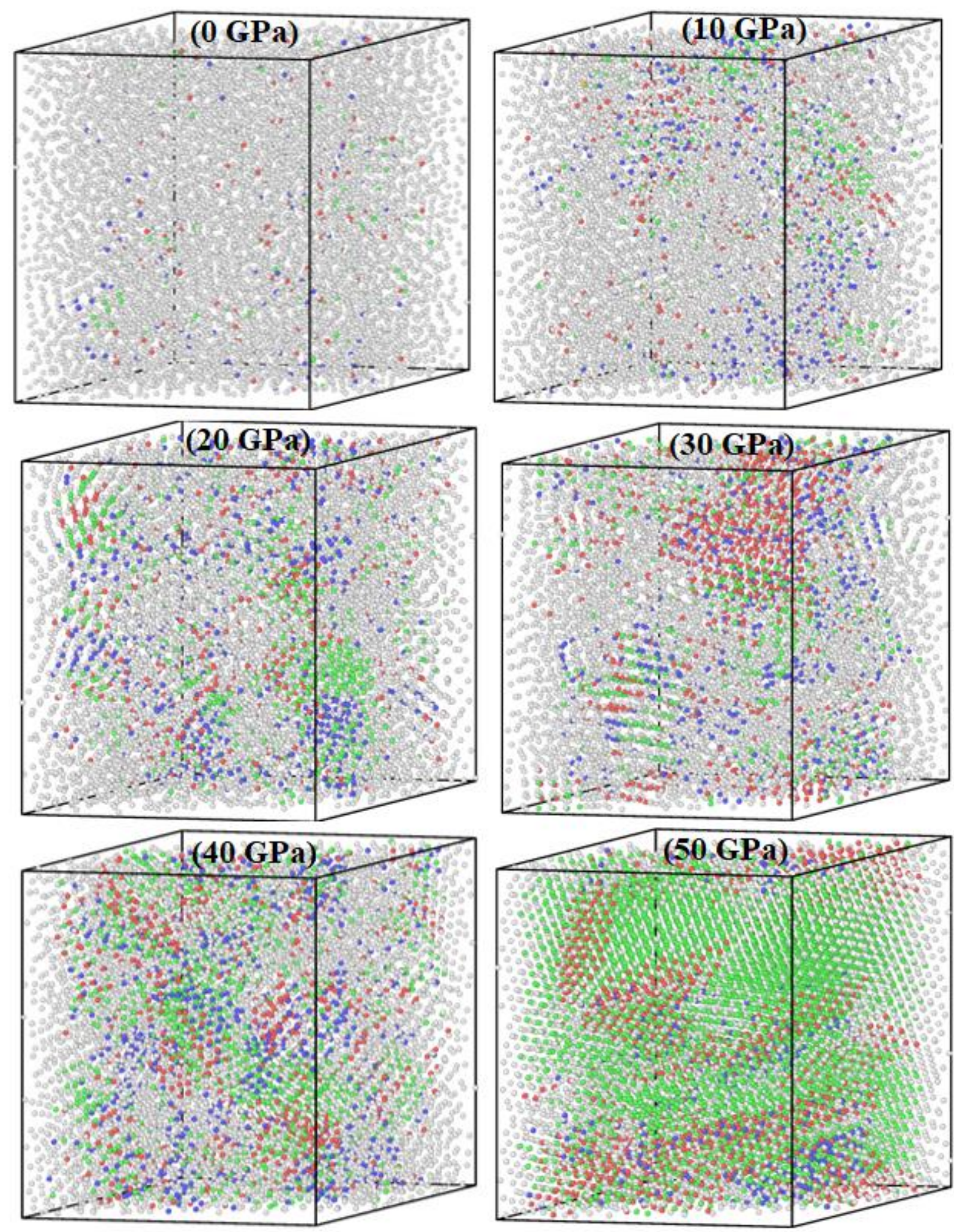

Figure 6. The evolution of crystalline-like clusters under the pressures of 0-50 GPa at $300 \mathrm{~K}$. Green, brown, blue and grey atoms represent fcc-like, hcp-like, bcc-like and other-like atoms, respectively. 


\subsection{Voronoi Tessellation (VT) Analysis}

We used the Voronoi tessellation (VT) method to clearly define the structure of the clusters, which according to HA analysis provides a more complete geometrical construction of a central atom to its neighboring atoms. Voronoi polyhedral index is expressed as $\left\langle n_{3}, n_{4}, n_{5}, \ldots, n_{i}, \ldots\right\rangle$, where $n_{i}$ donates the number of $i$-edged faces of the Voronoi polyhedrons (VPs). According to Voronoi analysis, the first group is the Voronoi indices of the perfect polyhedron (icos) $\langle 0,0,12,0\rangle$, and the distorted polyhedron (dicos) $\langle 0,2,8,2\rangle,\langle 0,1,10,2\rangle,\langle 0,3,6,3\rangle$, and $\langle 0,4,4,4\rangle[42]$. The second group is the Voronoi indices of the distorted fcc polyhedrons $\langle 0,3,6,4\rangle,\langle 0,3,6,5\rangle,\langle 0,4,4,6\rangle$, and $\langle 0,4,4,7\rangle[43]$. The last group represents the other most common polyhedrons, which $\langle 0,6,0,8\rangle$ and $\langle 0,2,8,4\rangle$ polyhedrons correspond to bcc-like clusters[44-46]. Figures 7 (a) - 7(d) show the dominant types of VPs in the system under different pressures, and the inset shows the 3D distribution of atoms with VP $\langle 0,4,4,6\rangle$ in MD simulation cell at $50 \mathrm{GPa}$.
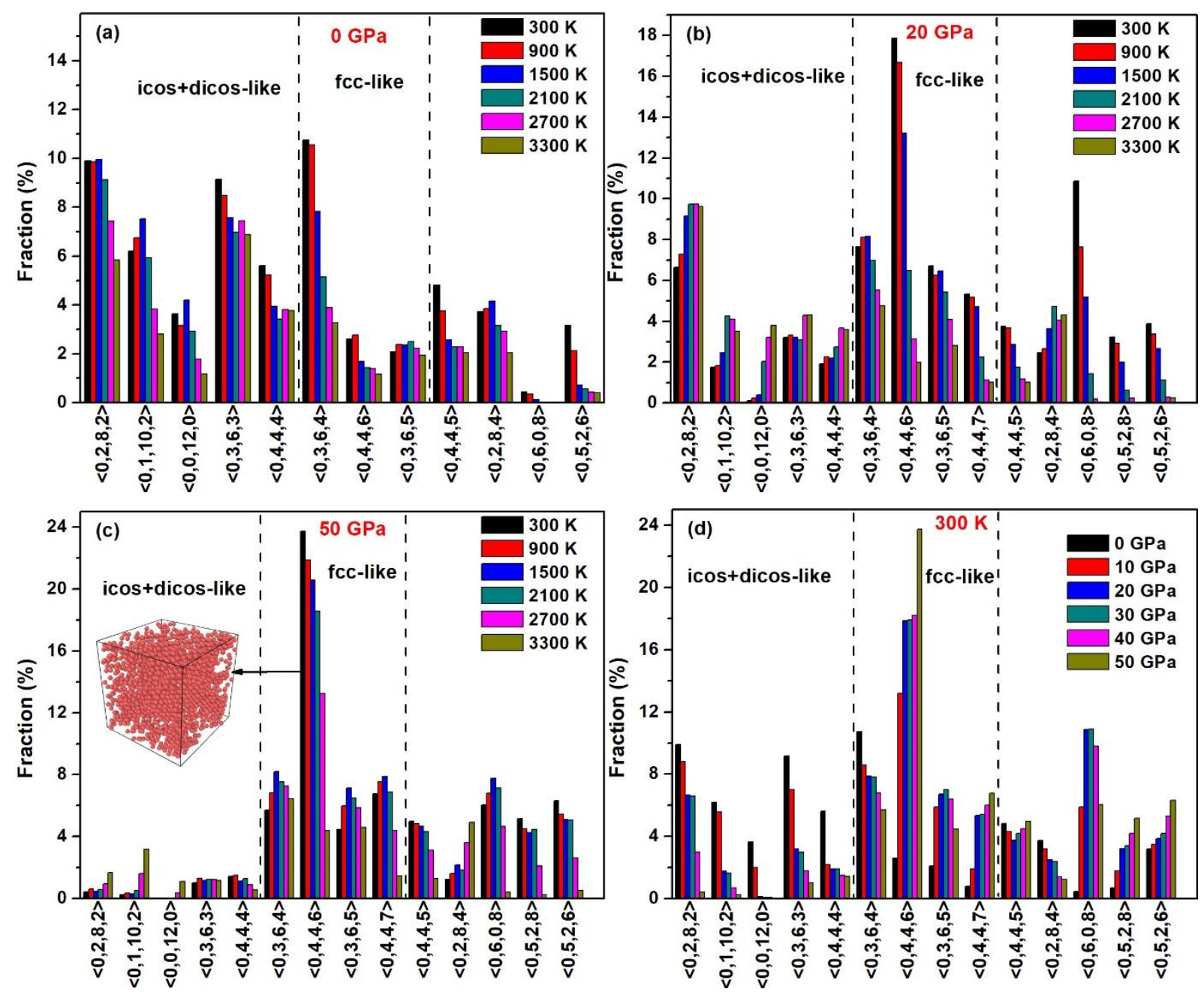

Figure 7. The results of VT analysis for monatomic hafnium at different temperatures under (a) 0, (b) 20, and (c) $50 \mathrm{GPa},(\mathrm{d})$ the pressure dependent change of dominant VPs at $300 \mathrm{~K}$. The inset illustrates the distribution of $\langle 0,4,4,6\rangle$ polyhedron under the pressure of $50 \mathrm{GPa}$ at $300 \mathrm{~K}$.

In the system cooled under $0 \mathrm{GPa}$, fcc and icos SRO play an important role according to Voronoi index analysis, as seen in Figure 7(a). The distribution of icos + dicos-like and fcc-like polyhedrons tends to increase with decreasing temperature, which is consistent with the results of the above-mentioned HA. When the pressure is increased to $20 \mathrm{GPa}$, the fraction of icos + dicos-like clusters decreases with the decreasing temperature, whereas the fraction of fcc-like clusters increases significantly. It can be clearly seen that the fraction of VPs changes with pressure, indicating the significant changes in local atomic structures among the systems under different pressures although the PDFs obtained between $0 \mathrm{GPa}$ and $40 \mathrm{GPa}$ exhibit amorphous-like behavior. Finally, at $50 \mathrm{GPa}$, the distribution of the icos + dicos type 
polyhedrons in the system drops rapidly, while the distribution of the fcc-like polyhedrons increases markedly, indicating that the system is a structural transition from an amorphous-like structure to a crystal-like structure. These results are consistent with results of the PDF and the HA analysis aforementioned above. Furthermore, during the rapid solidification of the monatomic metallic liquid hafnium, it appears that there exists a competition of the clusters among dicos clusters, defective fcc clusters, and defective bcc clusters. In the present case, it has been observed that the number of fcc-type base clusters increased with the increase in pressure. Figure 8 shows some of the clusters common in systems cooled under different pressures, which have been drawn using VESTA software[47].

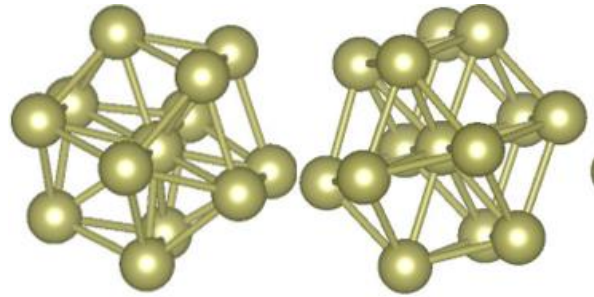

$\langle\mathbf{0 , 2 , 8 , 2 \rangle}$

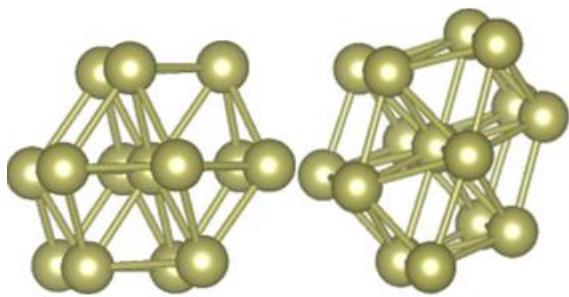

$\langle 0,3,6,4\rangle$

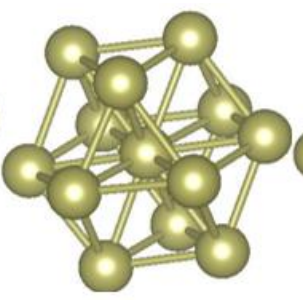

$\langle\mathbf{0 , 0 , 1 2 , 0 \rangle}$

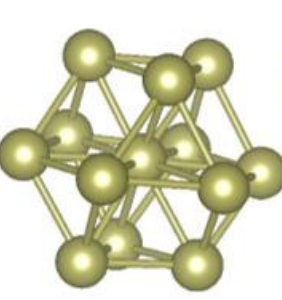

$\langle 0,3,6,3\rangle$

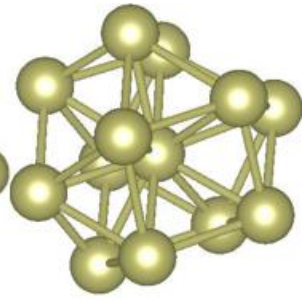

$\langle\mathbf{0 , 4 , 4 , 4 \rangle}$

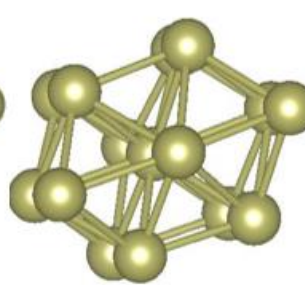

$\langle 0,3,6,5\rangle$

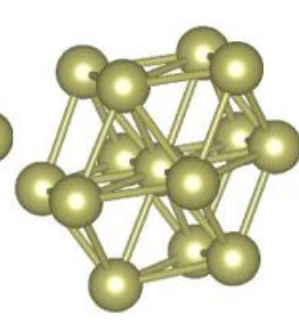

$\langle 0,4,4,5\rangle$

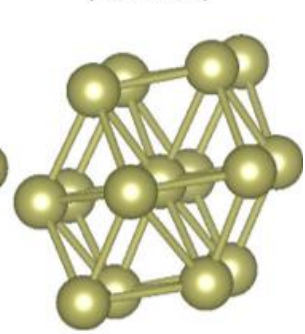

$\langle 0,6,0,8\rangle$

Figure 8. Representative atomic clusters of the most common for monatomic hafnium

\section{Conclusion}

Structural evolution of monatomic metallic liquid hafnium cooled with cooling rate of $2 \times 10^{13} \mathrm{Ks}^{-1}$ under different pressures is investigated by TB-MD simulations. When the system cooled under the pressures of 10-40 GPa, with decreasing temperature, a splitting at the second peak of the PDF curve and a shoulder between the first and second peaks of the PDF begin to appear, indicating that the system has undergone significant changes in its microstructure. In the PDF curves obtained under the pressure of $50 \mathrm{GPa}$, a sharper and more pronounced new peak appears at the position of the shoulders formed in the other pressures, indicating that this system is crystallized. These results mean that with the increase in pressure, the distance between the atoms within the system decreases, the order degree of glassy hafnium decreases, and the crystal nucleation in the system continues to increase. The results show that the $\mathrm{T}_{\mathrm{g}}$ is increased almost linearly with the increasing pressure as expected. The fraction of fccthcp-like $(1421+1422)$ bond-pairs increases remarkably with pressure, while the fraction of icos+deficos-like $(1551+1431+1541)$ bond-pairs decreases. Especially the distribution of the fcc-like 1421 bond pairs increases (the distribution of icos-like 1551 bond pairs decreases) from 10\% ( 18.2\%) in glass hafnium formed under $0 \mathrm{GPa}$ to $\sim 31.8 \%(\sim 4 \%)$ in glass formed under $40 \mathrm{GPa}$ at $300 \mathrm{~K}$. In the system cooled under pressure of $0 \mathrm{GPa}$, fcc and icos SRO play an important role according to Voronoi index analysis. When the pressure is increased from $0 \mathrm{GPa}$ to $50 \mathrm{GPa}$, the fraction of icos + dicos-like clusters decreases with the decreasing temperature, whereas the fraction of fcc-like clusters increases significantly. It has been seen that the HP produces an effect in favor of the liquid-to-crystalline transition during the rapid cooling of the monatomic liquid hafnium. However, the applied HP weakens the icosahedral order and increases the fraction of other clusters in glassy hafnium at low temperatures. As a result, the pressure, especially on the main clusters in the system, has a significant influence on the glass formation and evolution of microstructures. 


\section{References}

1. Chupas P. J., Chapman K. W., Lee P. L. 2007. Applications of an amorphous silicon-based area detector for high-resolution, high-sensitivity and fast time-resolved pair distribution function measurements, Journal of Applied Crystallography, 40: 463-470.

2 . Li R., Wang L., Li L., Yu T., Zhao H., Karena W., Wang Y., Rivers M. L., Chupas P. J., Mao H. 2017. Local structure of liquid gallium under pressure, Scientific Reports, 1-7.

3. Inoue A. 2000. Stabilization of metallic supercooled liquid and bulk amorphous alloys, Acta Materialia, 48 (1): 279-306.

4. Johnson W. L. 1999. Bulk Glass-Forming Metallic Alloys: Science and Technology, MRS Bulletin, 24: 42-56.

5. Duan G., Xu D., Zhang Q., Zhang G., Cagin T., Johnson W. L., Goddard W. A. 2005. Molecular dynamics study of the binary Cu46Zr54 metallic glass motivated by experiments: Glass formation and atomic-level structure, Physical Review B, 71 (22): 224208.

6. Qi L., Dong L. F., Zhang S. L., Ma M. Z., Jing Q., Li G., Liu R. P. 2008. Cluster evolution in the rapid cooling process of $\mathrm{Cu}-\mathrm{Ag}$ melts under high pressure: Molecular-dynamics simulation, Computational Materials Science, 43 (4): 732-735.

7 . Bhat M. H., Molinero V., Soignard E., Solomon V. C., Sastry S., Yarger J. L., Angell C. A. 2007. Vitrification of a monatomic metallic liquid, Nature, 448: 787.

8 . Zhong L., Wang J., Sheng H., Zhang Z., Mao S. X. 2014. Formation of monatomic metallic glasses through ultrafast liquid quenching., Nature, 512 (7513): 177-80.

9. Ercolessi F., Andreoni W., Tosatti E. 1991. Melting of small gold particles: Mechanism and size effects, Physical Review Letters, 66 (7): 911-914.

10 . Qin J., Gu T., Yang L. 2009. Structural and dynamical properties of Fe78Si9B13 alloy during rapid quenching by first principles molecular dynamic simulation, Journal of Non-Crystalline Solids, 355 (48-49): 2333-2338.

11. Jiang D., Wen D., Tian Z., Liu R. 2016. Glass formation and cluster evolution in the rapidly solidified monatomic metallic liquid Ta under high pressure, Physica A: Statistical Mechanics and its Applications, 463: 174-181.

12. Liu J., Zhao J. Z., Hu Z. Q. 2006. Pressure effect on the formation and the thermal stability of glassy $\mathrm{Cu}$, Computational Materials Science, 37 (3): 234-238.

13. Zhang Y., Wang L., Wang W., Liu X., Tian X., Zhang P. 2004. Pressure effect on the structural transition of liquid $\mathrm{Au}$, Physics Letters A, 320: 452-458.

14. Mo J., Liu H., Zhang Y., Wang M., Zhang L., Liu B., Yang W. 2017. Effects of pressure on structure and mechanical property in monatomic metallic glass, Journal of Non-Crystalline Solids, 464: $1-4$.

15. Qi L., Feng S., Xu N., Jing Q., Li G., Liu R. 2015. Pressure-induced Structures and Structural Evolution in Iron, Materials Research, 18: 78-82.

16. Celik F. A., Kazanc S., Yildiz A. K., Ozgen S. 2008. Pressure effect on the structural properties of amorphous Ag during isothermal annealing, Intermetallics, 16 (6): 793-800. 
17. Celtek M., Canan C., Domekeli U., Sengul S. 2017. Effect of pressure on microstructure evolution of bulk liquid hafnium during rapid solidification: a classical molecular dynamics simulation study, In International Scientific Conference “UNITECH 2017”-Gabrovo (pp. 230-235). Bulgaria.

18. Wen D., Deng Y., Liu J., Tian Z., Peng P. 2017. Effect of high pressure on the formation and evolution of clusters during the rapid solidification of zirconium melts, Computational Materials Science, 140: 275-283.

19. Lin D., Wang Y., Shang S., Lu Z., Liu Z., Hui X. 2013. A new many-body potential with the second-moment approximation of tight-binding scheme for Hafnium, Science China: Physics, Mechanics and Astronomy, 56 (11): 2071-2080.

20 . Phythian W. J., Stoller R. E., Foreman A. J. E., Calder A. F., Bacon D. J. 1995. A comparison of displacement cascades in copper and iron by molecular dynamics and its application to microstructural evolution, Journal of Nuclear Materials, 223 (3): 245-261.

21 . Foreman A. J. E., Phythian W. J., English C. A. 1992. The molecular dynamics simulation of irradiation damage cascades in copper using a many-body potential, Philosophical Magazine A, 66 (5): 671-695.

22. Shim J. H., Lee H. J., Wirth B. D. 2006. Molecular dynamics simulation of primary irradiation defect formation in Fe-10\%Cr alloy, Journal of Nuclear Materials, 351 (1-3): 56-64.

23. Bakanova A. A., Dudoladov I. P., Sutulov Y. N. 1969. Electron transitions in Hf, Eu and Yb at high pressures, Fizika Tverdogo Tela, 11: 1881.

24 . Ming L., Manghnani M. H., Katahara K. W. 1981. Investigation of a $\rightarrow$ w transformation in the ZrHf system to $42 \mathrm{GPa}$, Journal of Applied Physics, 52 (3): 1332-1335.

25 . Xia H., Parthasarathy G., Luo H., Vohra Y. K., Ruoff A. L. 1990. Crystal structures of group IVa metals at ultrahigh pressures, Physical Review B, 42 (10): 6736-6738.

26. Pandey K. K., Gyanchandani J., Somayazulu M., Dey G. K., Surinder Sharma M., Sikka S. K. 2014. Reinvestigation of high pressure polymorphism in Hafnium metal, Journal of Applied Physics, 115: 233513.

27. Smith W., Forester T. R. 1996. DL_POLY_2.0: A general-purpose parallel molecular dynamics simulation package, Journal of Molecular Graphics, 14 (3): 136-141.

28. Kittel C. 1986. Introduction to Solid State Physics. New York: John Wiley Sons Inc.

29. Cleri F., Rosato V. 1993. Tight-binding potentials for transition metals and alloys, Physical Review B, 48 (1): 22-33.

30 . Celtek M., Sengul S., Domekeli U., Canan C. 2016. Molecular dynamics study of structure and glass forming ability of Zr70Pd30 alloy, The European Physical Journal B, 89 (3): 1-6.

31. Dalgic S. S., Celtek M. 2011. Glass forming ability and crystallization of CuTi intermetallic alloy by molecular dynamics simulation. Journal of Optoelectronics and Advanced Materials, 13: 15631569 .

32. Sengul S., Celtek M., Domekeli U. 2017. Molecular dynamics simulations of glass formation and atomic structures in Zr60Cu20Fe20 ternary bulk metallic alloy, Vacuum, 136: 20-27.

33. Celtek M., Sengul S., Domekeli U. 2017. Glass formation and structural properties of Zr50Cu50xAlx bulk metallic glasses investigated by molecular dynamics simulations, Intermetallics, 84: 6273. 
34 . Celtek M., Sengul S. 2018. The characterisation of atomic structure and glass-forming ability of the $\mathrm{Zr}-\mathrm{Cu}-\mathrm{Co}$ metallic glasses studied by molecular dynamics simulations, Philosophical Magazine, 98 (9): 783-802.

35 . Li J. H., Kong L. T., Liu B. X. 2004. Structural transition and glass-forming ability of the Ni-Hf system studied by molecular dynamics simulation, Journal of Materials Research, 19 (12): 35473555.

36. Caprion D., Schober H. R. 2003. Computer simulation of liquid and amorphous selenium, Journal of Non-Crystalline Solids, 326: 369-373.

37. Wang L., Peng C., Wang Y., Zhang Y. 2006. Relating nucleation to dynamical and structural heterogeneity in supercooled liquid metal, Physics Letters A, 350: 69-74.

38. Honeycutt J. D., Andersen H. C. 1987. Molecular Dynamics Study of Melting and Freezing of Small Lennard- Jones Clusters, Journal of Physical Chemistry, 91 (24): 4950-4963.

39. Voronoi G. 1908. New Parametric Applications Concerning the Theory of Quadratic Forms Second Announcement, J. Reine Angew. Math., 134: 198-287.

40. Kazanc S. 2006. Molecular dynamics study of pressure effect on glass formation and the crystallization in liquid CuNi alloy, Computational Materials Science, 38 (2): $405-409$

41. Stukowski A. 2010. Visualization and analysis of atomistic simulation data with OVITO-the Open Visualization Tool, Modelling and Simulation in Materials Science and Engineering, 18 (1): 15012.

42. Finney J. L. 1970. Random packings and the structure of simple liquids I.The geometry of random close packing, Proc.Roy. Soc. Lond. A, 319: 479-493.

43. Rein ten Wolde P., Ruiz-Montero M. J., Frenkel D. 1996. Numerical calculation of the rate of crystal nucleation in a Lennard-Jones system at moderate undercooling, The Journal of Chemical Physics, 104 (24): 9932-9947.

44 . Cape J., Finney J., Woodcock L. V. 1981. An analysis of crystallization by homogeneous nucleation in a 4000-atom soft-sphere model, The Journal of Chemical Physics, 75 (5): 2366-2373.

45 . Yamamoto R., Doyama M. 1979. The polyhedron and cavity analyses of a structural model of amorphous iron, Journal of Physics F: Metal Physics, 9 (4): 617.

46. Tanaka M. 1986. Statistics of Voronoi Polyhedra in Rapidly Quenched Monatomic Liquids I. Changes During Rapid-Quenching Process, Journal of the Physical Society of Japan, 55 (9): 31083116.

47 . Momma K., Izumi F. 2011. VESTA 3 for three-dimensional visualization of crystal, volumetric and morphology data, Journal of Applied Crystallography, 44 (6): 1272-1276. 